Hak, E., Loon, S. van, Buskens, E., Essen, G.A. van, Bakker, D. de, Tacken, M.A.J.B.,

Hout, B.A. van, Grobbee, D.E., Verheij, T.J.M.

Design of the Dutch prevention of influenza, surveillance and management (PRISMA) study.

Vaccine: 21, 2003, nr. 15, p. 1719-1724

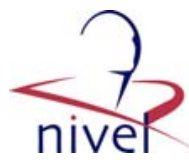

\begin{tabular}{|l|l|}
\hline Postprint Version & 1.0 \\
\hline Journal website & $\mathrm{http}: / /$ www.sciencedirect.com/ \\
\hline Pubmed link & $\begin{array}{l}\text { http://www.ncbi.nlm.nih.gov/entrez/query.fcgi?cmd=Retrieve\&db=pubmed\&dop } \\
\mathrm{t}=\text { Abstract\&list_uids=12639495\&query_hl=100\&itool=pubmed_docsum }\end{array}$ \\
\hline DOI & $10.1016 / \mathrm{S} 0264-410 \mathrm{X}(02) 00520-0$
\end{tabular}

* Corresponding author. Tel.: +31-30-253-8214; fax: +31-30-253-9028. E-mail address:

e.hak@med.uu.nl (E. Hak). URL: http://www.juliuscenter.nl. 1 Fax: +31-30-2729-729. 2 Fax: +31-

2435-40166.

\title{
Design of the Dutch Prevention of Influenza, Surveillance and Management (PRISMA) study
}

\author{
E. HAK ${ }^{\mathrm{A}, *}$, S. VAN LOON ${ }^{\mathrm{A}}$, E. BUSKENS ${ }^{\mathrm{A}}$, G.A. VAN ESSEN ${ }^{\mathrm{A}}$, D. DE BAKKER ${ }^{\mathrm{B}, 1}$, M.A.J.B. TACKEN ${ }^{\mathrm{C}, 2}$, \\ B.A. VAN HOUT ${ }^{\mathrm{A}}$, D.E. GROBBEE ${ }^{\mathrm{A}}$, TH.J.M. VERHEIJ ${ }^{\mathrm{A}}$ \\ a Julius Center for Health Sciences and Primary Care, P.O. Box 85060, 3508 AB, Utrecht, The \\ Netherlands \\ b National Institute for Primary Health Care, P.O. Box 1568, 3500 BN, Utrecht, The Netherlands \\ c Centre for quality of care research, P.O. Box 9101, 6500 HB, Nijmegen, The Netherlands
}

\begin{abstract}
Rationale and design of a study on the cost-effectiveness of the Dutch influenza vaccination campaign are described. During two influenza epidemics, about 75,000 primary care patients recommended for influenza vaccination are included. Cases have fatal or non-fatal influenza, pneumonia, otitis media, acute respiratory disease (ARD), heart failure, myocardial infarction, depression or diabetes dysregulation. Per case four controls are sampled, frequency matched on age and high-risk co-morbidity $(<18$ years, $18-64$, $\geq 65$ healthy, $\geq 65$ with co-morbidity). Baseline and outcome data are retrieved from patient records. During the 1999-2000 influenza A epidemic 5891 (7.9\%) high-risk children, 24,848 (33.2\%) high-risk adults aged 18-64 years, 18,484 (24.7\%) elderly with co-morbidity and 25,527 (34.1\%) healthy elderly had been included. The mortality rate was 5.2 per 1000 and 2035 non-fatal outcome events were recorded (incidence rate 27.2/1000).
\end{abstract}

\section{INTRODUCTION}

Worldwide, influenza is a major cause of annual morbidity and mortality with considerable economic impact [1]. Influenza can predispose for serious complications including viral or secondary bacterial pneumonia [2,3], otitis media [4], exacerbations of lung [5] or cardiac disease [6,7] often leading to treatment in primary care and sometimes requiring hospitalization [8]. In the US for example, hundreds of thousands excess hospital admissions due to influenza occur each year [9]. In The Netherlands it has been estimated that influenza accounts for 3713 and 744 days of hospitalization per 100,000 high-risk and low-risk elderly, respectively [10]. In the US, UK, Denmark and The Netherlands, 20,000 [11], 11,000 [12], 400 [13] and 2000 [14] excess deaths occur during influenza epidemics.

The main option to reduce the impact of influenza is immunoprophylaxis with conventional inactivated trivalent influenza vaccine $[15,16]$. In Dutch influenza immunization guidelines vaccination is recommended for persons with chronic heart disease, lung or renal disease, diabetes or other immune-related disease of all ages, and otherwise healthy elderly [17]. From data obtained in 
Hak, E., Loon, S. van, Buskens, E., Essen, G.A. van, Bakker, D. de, Tacken, M.A.J.B.,

Hout, B.A. van, Grobbee, D.E., Verheij, T.J.M.

Design of the Dutch prevention of influenza, surveillance and management (PRISMA) study.

Vaccine: 21, 2003, nr. 15, p. 1719-1724

general practice we estimated that approximately one-fifth of the patient population is targeted for vaccination [18]. At a national level this implies that 2.5-3 million individuals are eligible for vaccination. From 1995 to 1997, the Dutch general practice-based influenza immunization campaign succeeded in a high-vaccine coverage (between 76 and 84\%) among the target group [19] corresponding with several million doses at a cost of more than 30 million EURO annually.

Although many studies have been performed to establish the impact of large-scale vaccination, most effectiveness studies were conducted among selected subsections of the total population considered indicated, particularly the elderly [20-23]. In the latter, the vaccine appeared to reduce mortality by $40-50 \%$ and the need for hospitalization for influenza or pneumonia was reduced by $35 \%$ or more. However, almost half of the target population is aged under 65 years [18]. Surprisingly, no data are available to support the assumption that the health benefits from vaccination are similar among this younger age-group. Also, limited data are available on the vaccine's effectiveness in reducing the incidence of otitis media episodes [4], myocardial infarctions [6,24,25] or congestive heart failure [7], diabetes events [26] or exacerbations of lung disease $[5,27,28]$. In addition, cost-effectiveness analyses were restricted to both the elderly population and the traditionally used endpoints hospitalization for pneumonia or influenza and death [11,22,29-33]. Obviously, this has resulted in incomplete estimates of the cost-effectiveness of the total prevention program.

Since policy makers need accurate information to prioritize health care measures, valid studies assessing the health economic impact are required. This report describes the design of the Dutch Prevention of Influenza, Surveillance and Management (PRISMA) study — a cost-effectiveness study designed as a nested case-control study carried out in computerized general practices. The primary objective of this study is to determine the effectiveness of influenza vaccination in reducing the occurrence of acute episodes of fatal or non-fatal influenza, pneumonia, congestive heart failure, myocardial infarction, stroke, diabetes events, otitis media, depression, and other acute respiratory disease. Moreover, the associated costs (benefits) are estimated from a societal perspective. A second objective of the study is to assess the impact of the presence of co-morbidity, age or other prognostic information on the cost-effectiveness ratios. The results of PRISMA can be used to support the efficient allocation of budgets with regard to large-scale prevention of influenza.

\section{METHODS}

\subsection{Source population}

Study patients for the case-control study are chosen from among a non-selected population of patients targeted for annual influenza vaccination according to Dutch immunization guidelines [17]. During the 1999-2000 and 2001-2002 influenza seasons, the seasonal dynamic cohorts of study patients are identified within two large computerized general practice networks of the Julius Center for General Practice and Patient Oriented Research [34] and the National Information Network of GPs (LINH) [35]. In both networks the general practitioners (GPs) routinely record encoded patient information using a general practitioner information system. During the 1999-2000 season, 93 practices participated and it is expected that the same number of practices participates during the 2001-2002 season. The 2000-2001 influenza season appeared to be non-epidemic and data were not collected.

As of November 1999 and 2001, eligible patients are selected by means of a dedicated software module. Details on the module's stepwise selection procedure have been reported previously [18]. In short, patients are identified by their age ( $\geq 65$ years, including patients who become 65 before next May) and/or presence of high-risk co-morbidity as indicated by International Classification of Primary Care (ICPC) diagnostic codes (R84 [maligne neoplasms lar/trach/bronc/lung], R91 [chronic bronchitis], R95 [emphysema], R96 [asthma], K74 [angina pectoris], K75 [myocardial infarction], K76 [chr. ischemic disease], K77 [heart failure], K78 [atrial fibrillation], K79 [paroxysmal tachycardia], K80 [ectopic beats], K82 [cor pulmonalis], K83 [heart valve disease], K84 [other heart disease], T90 [diabetes mellitus], U88 [glomerulonephritis], U99 [other disease urinary tract], S10 [boil/carbuncle]), Anatomical Therapeutic Classification (ATC) medical drug codes (Class C01, C03, $\mathrm{C} 07, \mathrm{~B} 01, \mathrm{~A} 10, \mathrm{~J} 01, \mathrm{R} 03$ ), or a tag in their computerized records indicating chronic pulmonary or heart disease, diabetes mellitus, renal disease or chronic presence of boils. Since all medical data are 
Hak, E., Loon, S. van, Buskens, E., Essen, G.A. van, Bakker, D. de, Tacken, M.A.J.B.,

Hout, B.A. van, Grobbee, D.E., Verheij, T.J.M.

Design of the Dutch prevention of influenza, surveillance and management (PRISMA) study.

Vaccine: 21, 2003, nr. 15, p. 1719-1724

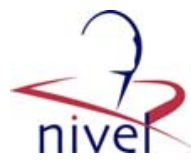

supplied anonymously to the Julius Center, individual patient consent is not obtained. The Ethics Committee of the University Medical Center Utrecht approved the conduct of the study.

\subsection{Identification of cases and controls during the epidemics}

Study patients are identified as a case if influenza might have played a role in the etiology of the disease according to the literature. The following physician-diagnoses within the timeframe of the epidemic of the pertaining season were considered to indicate a case: fatal or non-fatal influenza (ICPC code R80), pneumonia (R81), otitis media (H71), myocardial infarction (K75), stroke (K90), or depression (P76). In addition, subjects who were referred to hospital or treated with oral prednisolone for acute respiratory disease (ARD) (R78, R91, R95, R96), or patients referred to hospital for congestive heart failure (K77) or diabetes dysregulation (T90) during either epidemic are considered cases. The epidemic periods are defined as the weeks in which the incidence of influenza-like-illness reported by the sentinel practices is above four per 10,000 inhabitants per week [36]. In The Netherlands, annual influenza surveillance is carried out by the National Influenza Center in collaboration with the Sentinel Practice Network [36]. In season one (1999-2000), the epidemic occurred between week 50 of 1999 and week 10 of 2000 as we defined similarly in a previous study [8] in which we observed vaccine effectiveness of 50\% in among elderly patients with chronic lung disease in general practice. During that season, clinical influenza activity was predominantly associated with influenza A(H3N2) Sydney-type [36]. The status of the disease endpoint (acute or chronic) is verified retrospectively for all potential cases in the patient records by participating GPs or a research physician $(\mathrm{SvL})$.

Case patients are stratified according to mutually exclusive groups on the basis of their age and presence of high-risk disease: (1) children under 18 years of age with high-risk co-morbidity, (2) adults aged between 18 and 64 years with high-risk co-morbidity, (3) elderly patients aged 65 years or over with co-morbidity, and (4) otherwise healthy elderly over 65 years. For each case within one of the four prognostic strata, four control patients are randomly selected from the remainder of that season's cohort within the same stratum.

\subsection{Assessment of influenza vaccination status}

In The Netherlands, persons with an indication for vaccination are offered the influenza vaccine through a standard prevention program in primary care [19]. Approximately one-fifth of the persons fail to receive the vaccine which enables the comparison between exposed and non-exposed. The trivalent sub-unit influenza vaccine matched well with circulating influenza A and B strains in the 1999-2000 influenza season as quantified by high-hemaglutinin inhibition (HAI) titers in ferret sera at the National Influenza Center [36].

A person is assumed to have been vaccinated if the code for influenza vaccination (R44.1) is present in the medical records in the period October-November prior to the pertaining influenza season. Unpublished data of our group showed that the confirmed information on exposure status before either epidemic was in high agreement with the absence/ presence of the ICPC-code for vaccination R44.1 ( $\mathrm{K}$ was 93\%). Approximately one-fifth of indicated persons do not receive the vaccine [19].

\subsection{Prognostic data}

Base-line demographic information, including age, sex and health insurance coverage (private or National Health Service) is collected using the above-mentioned software module [18]. Further detailed information is obtained on potential prognostic factors by review of medical records. In accordance with previous reports $[7,8,22,23,34]$ the presence of relevant co-morbidity and referral to a specialist and hospitalization in the 12 months preceding the epidemic are registered. Also, influenza vaccination status in the previous season and chronic use of medications is recorded. The numbers of GP consultations in the preceding year is counted and recognized as an indicator of disease severity and medical consumption.

\subsection{Direct costs}

Direct costs of the vaccination program including purchase costs of the vaccine, supplies, vaccine administration and program costs are calculated by using the total annual costs of 30 million EURO and the average number of 2.4 million vaccine doses purchased centrally at the National Institute for Public Health and the Environment, Bilthoven in 1997 (12.4 EURO per person) [35]. Since it has been 
Hak, E., Loon, S. van, Buskens, E., Essen, G.A. van, Bakker, D. de, Tacken, M.A.J.B.,

Hout, B.A. van, Grobbee, D.E., Verheij, T.J.M.

Design of the Dutch prevention of influenza, surveillance and management (PRISMA) study.

Vaccine: 21, 2003, nr. 15, p. 1719-1724

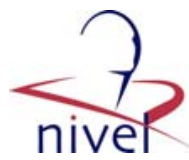

established that vaccination has no major side effects, [15] costs due to adverse events are not included [1]. Direct medical costs of health care associated with morbidity from influenza are calculated from the data of a sample of cases. These costs include GP practice visits, medical prescriptions, costs of diagnostic tests, hospitalization, transport by ambulance and use of intensive care facilities.

Indirect costs of vaccination include costs of productivity loss in the working-age population between 18 and 64 years only (stratum 2) and of parents of children in the youngest group (stratum 1). These costs are estimated using the figures supplied by the National Bureau of Statistics on the proportion of persons within these strata. In accordance with a previous study [1], we assume that vaccination would take $1 \mathrm{~h}$ of working time. Costs are calculated assuming that the costs associated with loss in productivity are made per hour.

Indirect costs of productivity loss due to morbidity from influenza are calculated using the absenteeism register of a large Dutch company employing over 5000 persons. For all productivity losses the age-adjusted values for the present value of future earnings at a $4 \%$ discount rate are used.

\subsection{Sample size and data analysis}

Prior to the start of the study in September 2000, we used EPI-INFO software (version 6, CDC, Atlanta, USA) to estimate the sample size needed. Assuming a vaccination rate of $84 \%$ [19], a casecontrol ratio of 1:4 and a two-tailed $\alpha$ level of 0.05 , a seasonal study population of 500 cases and 2000 controls per stratum would give us a statistical power of $80 \%$ to detect an expected stratum-specific odds ratio for vaccination of 0.7 or lower (i.e. reduction $\geq 30 \%$ ). This low vaccine effectiveness estimate takes into account potential random misclassification of the outcomes due to other viruses involved in the etiology of complications [7]. Pooled data of two seasons using twice the number of person-periods of observation [22] would result in a higher statistical power of more than $90 \%$ to detect the same reduction and enables subgroup analysis.

Uni- and multivariate logistic regression modeling is used to obtain crude and adjusted odds ratios and their $95 \%$ confidence intervals (CI) of vaccine effectiveness. In the first stage of constructing the multivariate model vaccination status is defined as the exposure term and the case status as the dependent variable. Each potential confounding variable is added independently to the model to assess its effect on the estimated vaccine effectiveness. In the final model we intend to include only those variables that materially $(>5 \%)$ alter the odds ratio for influenza vaccination. The same approach is applied to obtain adjusted odds ratios in the complete study population as well as in the four prognostic strata. Differences in vaccine effect by stratum and season (effect modification) is statistically tested by adding the variable vaccination and its first-order interaction term with stratum or season to the final model. The adjusted odds ratios and their $95 \%$ confidence intervals are used as an approximation of the relative risk. The adjusted vaccine effectiveness is calculated as follows: (1adjusted odds ratio) $\times 100 \%$.

\subsection{Cost-effectiveness analysis}

Using an arithmetic model, i.e. a multi-state decision model, to integrate data on the probability of morbidity or mortality in patients on the basis of individual patient data and associated costs, the incremental costs per life-year gained is estimated. In addition, the incremental costs per complication averted is estimated as well. The analysis is repeated for each stratum separately. Also, multivariate sensitivity analysis will be performed, especially with regard to potential differences in effectiveness across the four main strata. The results obtained are intended to yield insight in the specific merits of providing influenza vaccination in each stratum.

\section{CURRENT STATUS AND FIRST RESULTS OF THE 1999-2000 EPIDEMIC}

In September 2000, all GP practices of both networks were asked to participate in the study. In all, 43 centers of the Julius Center Network and 48 centers of the National Information Network with a total patient population of approximately 340,000 patients enlisted gave their consent. In November 2000, we selected 74,750 persons ( $22 \%$ of the patient list) who required influenza vaccination according to the immunization guidelines (Table 1). The study population (season 1) comprised 5918 (7.9\%) highrisk children, 24,848 (33.2\%) high-risk adults aged 18-64 years, 18,484 (24.7\%) elderly with comorbidity and 25,527 (34.1\%) healthy elderly. Among the children and working-age patients, asthma 
Hak, E., Loon, S. van, Buskens, E., Essen, G.A. van, Bakker, D. de, Tacken, M.A.J.B.,

Hout, B.A. van, Grobbee, D.E., Verheij, T.J.M.

Design of the Dutch prevention of influenza, surveillance and management (PRISMA) study.

Vaccine: 21, 2003, nr. 15, p. 1719-1724

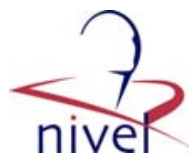

or other chronic pulmonary disease were the most common reason for vaccination. Among the elderly with concomitant disease, two-third had chronic cardiac disease and one-third chronic lung disease.

\section{[ TABLE 1 ]}

In all, 385 deaths were registered, only 6 among the adults and the remaining among the elderly (Table 2). Also, cardiovascular events were most common among elderly persons. Among the respiratory complications, acute respiratory disease was most common (13.2 per 1000 persons). Otitis media was mostly observed in children. Referrals for depression occurred among all adults and rates were not different for adults or elderly.

\section{[ TABLE 2 ]}

\section{DISCUSSION}

The PRISMA study is a nested case-control study in which clinical and economic data are collected in a nonselected primary care-based target population to determine the cost-effectiveness of the current nationwide influenza vaccination program. Results of the first seasonal study cohort confirm that half the vaccine target population is aged under 65 years, mostly with chronic pulmonary disease $[18,35]$.

Given current immunization rates, the mortality rate was 5.2 per 1000 and was highest among highrisk elderly (14.7 per 1000). In all, 32.4 events per 1000 persons occurred during the influenza epidemic and outcome events were three times higher in high-risk elderly than in other subsections of the target population. Otitis media episodes most frequently occurred among the children. Rates for respiratory illness among children were comparable with such rates among asthmatic children followed during two influenza epidemics [37]. Similarly, among the high-risk adults, rates for acute respiratory disease, pneumonia and death were comparable with data of an earlier study among patients with chronic lung disease aged 18 years or over who were followed during the 1995/96 influenza A epidemic [8].

Several decisions made in planning the PRISMA study warrant further explanation. First, we used a case-control design to study the vaccine's effectiveness. Preferably, a randomized controlled trial is used to study drug efficacy effects, since such a design is less vulnerable to bias. However, when considering a RCT for evaluation of influenza vaccines, many problems arise. The incidence of serious morbidity or mortality from influenza is low, large numbers of patients would have to be recruited making such a study very expensive. Second, several influenza seasons may need to be observed as the virulence of circulating influenza viral types is highly variable. Finally, once the vaccine has been licensed ethical concerns may be raised regarding the use of placebo-controlled studies, especially when persons at high risk for complications are involved. Although there is a potential for bias, non-experimental designs can be used to validly assess vaccine effects. A cohort design was deemed inefficient since many patient records would have to be reviewed. Information bias is reduced by the use of existing information in the records. Selection bias is limited by applying the case-control design in a prospectively followed cohort with ample prognostic information. Confounding, however, remains a major concern in these types of studies. In previous studies, it has been shown that vaccinees have more risk factors than non-vaccinees. We will apply several techniques to reduce the potential for such bias. (1) The study patients, both vaccinees and nonvaccinees are chosen from the current vaccine target group. (2) The vaccine effectiveness is estimated in four restricted prognostic strata. (3) Information on potential confounding variables such as age and gender, and indicators of disease severity is collected and used in multivariate analysis to assess the influence of these factors and the independent effect of vaccination.

Also, the choice of cases may be disputed. Studies traditionally showed an effect of vaccination on all-cause mortality or the occurrence of hospital admission for influenza or pneumonia. Apart from these endpoints, we also consider in the case definition other potentially influenza-related morbidity. Although only few studies assessed the relation between cardiac disease, diabetes events and acute 
Hak, E., Loon, S. van, Buskens, E., Essen, G.A. van, Bakker, D. de, Tacken, M.A.J.B.,

Hout, B.A. van, Grobbee, D.E., Verheij, T.J.M.

Design of the Dutch prevention of influenza, surveillance and management (PRISMA) study.

Vaccine: 21, 2003, nr. 15, p. 1719-1724

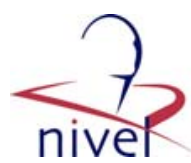

respiratory disease with influenza, the available data support the hypothesis that influenza might actually cause many excess episodes during epidemics, hence vaccination might reduce this disease and economic burden. In addition, acute depression episodes are possibly associated with the influenza incidence. Since depression has been associated with many chronic infectious diseases, we hypothesized that influenza might be related to this disease, especially when considering the potential long-term convalescence period of influenza infection among patients with co-morbidity.

Finally, the decision to adopt the perspective of society in the cost-effectiveness analysis is based on the fact that the influenza vaccination program is paid entirely by the Dutch government.We will also extend our cost-effectiveness analysis when the age-boundary is lowered down to 50 years as is the new policy in the US. Since commercial companies might encounter economic benefits if their personnel is vaccinated against influenza, we will also estimate potential savings using the data supplied by a commercial company as an example of commercial manufacturers in general by adopting the perspective of the payer.

\section{ACKNOWLEDGEMENTS}

We thank Mrs. N. Boekema-Bakker and Mrs. M.L. van den Haak, data managers, for their contribution to the data collection. Funding by the Dutch Health Insurance Board is greatly acknowledged.

\section{REFERENCES}

[1] Nichol KL, Goodman M. The health and economic benefits of influenza vaccination for healthy and at-risk persons aged 65 to 74 years. Pharmacoeconomics 1999;16(Suppl 1):63-71.

[2] Logar M. Microbial aetiology of community-acquired pneumonia in hospitalised patients. Eur J Clin Microbiol Infect Dis 1999;18:777- 82.

[3] Connolly AM, Salmon RL, Williams DH. What are the complications of influenza and can they be prevented? BMJ 1993;306:1452-4.

[4] Belshe RB, Mendelman PM, Treanor J, King J, Gruber WC, Piedra P, et al. The efficacy of live attenuated, cold-adapted, trivalent, intranasal influenza virus vaccine in children. $\mathrm{N}$ Engl J Med 1998;338:1405-12.

[5] Nicholson KG, Kent J, Ireland DC. Respiratory viruses and exacerbations of asthma in adults. BMJ 1993;307:982-6.

[6] Naghavi N, Barlas Z, Siadata S, Naguib S, Madjid M, Casscells W. Association of influenza vaccination and reduced risk of recurrent myocardial infarction. Circulation 2000;102:3039-45.

[7] Nichol KL, Margolis KL, Wuorenma J, Von Sternberg T. The efficacy and cost-effectiveness of vaccination against influenza among elderly persons in the community. N Engl J Med 1994;331:77884.

[8] Hak E, A G, Buskens E, Stalman WA, de Melker RA. Is immunising all patients with chronic lung disease in the community against influenza cost effective? Evidence from a general practice based prospective cohort study in Utrecht, The Netherlands. J Epidemiol Community Health 1998;52:120 5.

[9] Barker WH. Excess pneumonia and influenza associated hospitalization during influenza epidemics in the United States 1970-1978. Am J Public Health 1986;76:761-5.

[10] Postma M, Bos JM, Van Gennep M, Jager JC, Baltussen R, Sprenger MJW. Economic evaluation of influenza vaccination. Assessment for The Netherlands. Pharmacoeconomics 1999;16(suppl

1):33-40.

[11] Lui K-J, Kendal AP. Impact of influenza epidemics on mortality in the United States from October 1972 to May 1985. Am J Public Health 1987;77:712-6.

[12] Nicholson KG. Impact of influenza and respiratory syncitial virus on mortality in England and

Wales from January 1975 to December 1990. Epidemiol Infect 1996;116:51-63.

[13] Statens Institut for Medicinsk Teknologivurdering. Influenza vaccination of elderly (with abstract in English). Medicinsk Teknologivurdering 2000;2(1).

[14] Sprenger MJW, van Naelten MAMG, Mulder PGH, Masurel N. Influenza-related excess mortality in The Netherlands. Lancet 1990;336:382.

[15] Anonymous. Prevention and control of influenza. Recommendations of the Advisory Committee on Immunization Practice (ACIP). MMWR 2000;49:1-38.

[16] Couch RB. Prevention and treatment of influenza. N Engl J Med 2000;343:1778-87. 
Hak, E., Loon, S. van, Buskens, E., Essen, G.A. van, Bakker, D. de, Tacken, M.A.J.B.,

Hout, B.A. van, Grobbee, D.E., Verheij, T.J.M.

Design of the Dutch prevention of influenza, surveillance and management (PRISMA) study.

Vaccine: 21, 2003, nr. 15, p. 1719-1724

[17] van Essen GA, Kuyvenhoven MM, de Melker RA. Implementing Dutch College of General Practitioners' guidelines for influenza vaccination: an intervention study. Br J Gen Pract 1997;47: 259.

[18] Hak E, van Essen GA, Stalman W, de Melker RA. Improving influenza vaccination coverage among high-risk patients: the role of computerised medical records. Fam Pract 1998;15:138-43.

[19] Hak E, Hermens RPMG, Hoes AW, Verheij Th JM, Kuijvenhoven MM, van Essen GA. Effectiveness of a coordinated nationwide program to improve influenza immunisation rates in The Netherlands. Scand J Prim Health Care 2000;18:237-41.

[20] Gross PA, Hermogenes AW, Sacks HS, Lau J, Levandowski RA. The efficacy of influenza vaccine in elderly persons. A meta-analysis and review of the literature. Ann Intern Med 1995;123:518-27.

[21] Ohmit SE, Monto AS. Influenza vaccine effectiveness in preventing hospitalization for pneumonia among the elderly during influenza A and type B seasons. Int J Epidemiol 1995;24:1240-8.

[22] Nichol KL, Wuorenma J, Von Sternberg T. Benefits of influenza vaccination for low-, intermediateand high-risk senior citizens. Arch Intern Med 1998;158:1769-76.

[23] Flemming DM, Watson JM, Nicholas S, Smith GE, Swan AE. Study on the effectiveness of influenza vaccination in the elderly in the epidemic of 1989-90 using a general practice database. Epidemiol Infect 1995;115:581-9.

[24] Meier CR, Jick SS, Derby LE, Vasilakis C, Jick H. Acute respiratory-tract infections and risk of first-time acute myocardial infarction. Lancet 1998;351:1467-71.

[25] Siscovick DS, Raghunathan TE, Lin D, Weinmann S, Arbogast P, Lemaitre RM, et al. Influenza vaccination and the risk of primary cardiac arrest. Am J Epidemiol 2000;152:674-7.

[26] Valdez R, Narayan KM, Geiss LS, Engelgau MM. Impact of diabetes mellitus on mortality associated with pneumonia and influenza among non-Hispanic black and white US adults. Am J Public Health 1999;89:1715-21.

[27] Beasley R, Coleman ED, Hermon Y, Holst PE, O'Donnell TV, Tobias M. Viral respiratory infection and exacerbations of asthma in adult patients. Thorax 1988;43:679-83.

[28] Glezen WP, Greenberg SB, Atmar RL, Piedra PA, Cough RB. Impact of respiratory virus infections on persons with chronic underlying conditions. JAMA 2000;283:499-505.

[29] Mullooly JP, Bennett MD, Hornbrook MC, Barker WH, Williams WW, Patriarca PA, et al. Influenza vaccination programs for elderly persons: cost-effectiveness in a health maintenance organization. Ann Intern Med 1994;121:947-52.

[30] Riddiough MA, Sisk JE, Bell JC. Influenza vaccination. Costeffectiveness and public policy. JAMA 1983;249:3189-95.

[31] Maucher JM, Gambert SR. Cost-effectiveness analysis of influenza vaccination in the elderly. Age 1990;13:3-9.

[32] Patriarca PA, Arden NH, Koplan JP, Goodman RA. Prevention and control of type A influenza infections in nursing homes. Benefits and costs of four approaches using vaccination and amantadine. Ann Intern Med 1987;107:732-40.

[33] Helliwell BE, Drummond MF. The costs and benefits of preventing influenza Ontario's elderly. Can J Public Health 1988;79:175-9.

[34] Hak E, Verheij TJM, Van Essen GA, Lafeber AB, Grobbee DE, Hoes AW. Prognostic factors for influenza-associated hospitalization and death during an epidemic. Epidemiol Infect 2001;126:2618.

[35] Tacken MAJB, Braspenning JCC, van Paasen J, van den Hoogen HJM, de Bakker DH, Grol RPTM. Negen jaar influenzavaccinatie in de huisartspraktijk [in Dutch]. Huisarts Wet 2000;43:566-7.

[36] Rimmelzwaan GF, De Jong JC, Bartelds AI, Dorigo-Zetsma JW, Fouchier RA, Osterhaus AD. Influenza season 1999/2000; composition of vaccine for 2000/2001 [in Dutch]. Ned Tijdschr Geneeskd 2000;144:1968-71.

[37] Smits AJ, Hak E, Stalman WAB, Van Essen GA, Hoes AW, Verheij TJM. Clinical effectiveness of conventional influenza vaccination in asthmatic children. Epidemiol Infect 2002;128:205-11. 
Hak, E., Loon, S. van, Buskens, E., Essen, G.A. van, Bakker, D. de, Tacken, M.A.J.B.,

Hout, B.A. van, Grobbee, D.E., Verheij, T.J.M.

Design of the Dutch prevention of influenza, surveillance and management (PRISMA) study.

Vaccine: 21, 2003, nr. 15, p. 1719-1724

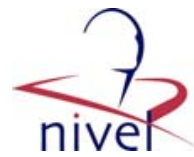

\section{TABLES}

Table 1

Indication criteria prior to the 1999-2000 influenza A epidemic

\begin{tabular}{|c|c|c|c|c|}
\hline Stratum & Indication criterion & $\begin{array}{l}\text { Network } 1 \quad(N=32,725) \\
N(\%)^{\mathrm{a}}\end{array}$ & $\begin{array}{l}\text { Network } 2(N=42,025) \\
N(\%)^{\mathrm{a}}\end{array}$ & $\begin{array}{l}\text { Total }(N=74,750) \\
N(\%)^{\mathrm{a}}\end{array}$ \\
\hline \multirow{6}{*}{$0-17$ years $(N=5,891)$} & Cardiovascular disease & $62(2.4)$ & $109(3.3)$ & $171(2.9)$ \\
\hline & Lung disease & $1,849(72.0)$ & $2,662(80.2)$ & $4,511(76.6)$ \\
\hline & Diabetes mellitus & $37(1.4)$ & $49(1.5)$ & $86(1.5)$ \\
\hline & Renal insufficiency & $16(0.6)$ & $23(0.7)$ & $39(0.7)$ \\
\hline & Immune-related & $648(25.2)$ & $532(16.0)$ & $1,180(20.0)$ \\
\hline & Total & $2,570(100)$ & $3,321(100)$ & $5,891(100)$ \\
\hline \multirow[t]{6}{*}{$18-64$ years $(N=24,848)$} & Cardiovascular disease & $1,945(18.1)$ & $2,833(20.10)$ & $4,778(19.2)$ \\
\hline & Lung disease & $4,828(44.9)$ & $6,368(45.19)$ & $11,196(45.1)$ \\
\hline & Diabetes mellitus & $1,795(16.7)$ & $2,221(15.76)$ & $4,016(16.2)$ \\
\hline & Renal insufficiency & $192(1.8)$ & $206(1.46)$ & $398(1.6)$ \\
\hline & Immune-related & $2,977(27.7)$ & $3,704(26.28)$ & $6,681(26.9)$ \\
\hline & Total & $10,756(100)$ & $14,092(100)$ & $24,848(100.0)$ \\
\hline \multirow[t]{6}{*}{$\mathrm{HR} \geq 65$ years $^{\mathrm{b}}(N=18,484)$} & Cardiovascular disease & $4,693(59.1)$ & $6,487(61.5)$ & $11,180(60.5)$ \\
\hline & Lung disease & $2,622(33.01)$ & $3,883(36.8)$ & $6,505(35.2)$ \\
\hline & Diabetes mellitus & $2,241(28.2)$ & $2,890(27.4)$ & $5,131(27.8)$ \\
\hline & Renal insufficiency & $331(4.2)$ & $254(2.4)$ & $585(3.2)$ \\
\hline & Immune-related & $343(4.3)$ & $422(3.9)$ & $765(4.1)$ \\
\hline & Total & $7,943(100)$ & $10,541(100)$ & $18,484(100.0)$ \\
\hline $\mathrm{LR} \geq 65$ years $^{\mathrm{b}}(N=25,527)$ & Total & $11,456(100)$ & $14,071(100)$ & $25,527(100.0)$ \\
\hline
\end{tabular}

a Percentage of the stratum total; patients might have two or more diseases and percentages can sum up to more than $100 \%$.

${ }^{\mathrm{b}} \mathrm{HR}$ : high-risk, LR: healthy persons (including persons of 64 years who became 65 years before May 2000).

Table 2

Incidence of morbidity and mortality (per 1000) during the 1999-2000 influenza A epidemic

\begin{tabular}{|c|c|c|c|c|c|}
\hline End point & $\begin{array}{l}\text { All ages } \\
(N=74,750) \\
N(\% 0)^{\mathrm{a}}\end{array}$ & $\begin{array}{l}<18 \text { years with } \\
\text { co-morbidity } \\
(N=5,891) N(\% 0)^{\mathrm{b}}\end{array}$ & $\begin{array}{l}18-64 \text { years with } \\
\text { co-morbidity } \\
(N=24,848) N(\% 0)^{\mathrm{b}}\end{array}$ & $\begin{array}{l}\geq 65 \text { healthy elderly } \\
(N=25,527) N(\% 0)^{\mathrm{b}}\end{array}$ & $\begin{array}{l}\geq 65 \text { years with } \\
\text { co-morbidity } \\
(N=18,484) N(\% o)^{b}\end{array}$ \\
\hline \multicolumn{6}{|l|}{ Respiratory illness } \\
\hline Influenza & $177(2.4)$ & $4(0.7)$ & $46(1.8)$ & $51(2.0)$ & $76(4.1)$ \\
\hline Pneumonia & $337(4.5)$ & $15(2.5)$ & $65(2.6)$ & $72(2.8)$ & $185(10.0)$ \\
\hline $\begin{array}{r}\text { Acute respiratory } \\
\text { disease (ARD) }\end{array}$ & $989(13.2)$ & $41(7.0)$ & $229(9.2)$ & $243(9.5)$ & $476(25.8)$ \\
\hline Otitis media & $134(1.8)$ & $74(12.6)$ & $15(0.6)$ & $11(0.4)$ & $34(1.8)$ \\
\hline \multicolumn{6}{|l|}{ Cardiovascular illness } \\
\hline Heart failure & $100(1.3)$ & $0(0.0)$ & $6(0.2)$ & $14(0.5)$ & $80(4.3)$ \\
\hline $\begin{array}{l}\text { Myocardial } \\
\text { infarction (MI) }\end{array}$ & $90(1.2)$ & $0(0.0)$ & $18(0.7)$ & $29(1.1)$ & $43(2.3)$ \\
\hline Stroke & $134(1.8)$ & $0(0.0)$ & $15(0.6)$ & $42(1.6)$ & $77(4.2)$ \\
\hline \multicolumn{6}{|l|}{ Other } \\
\hline Diabetes event & $123(1.6)$ & $2(0.3)$ & $61(2.4)$ & $2(0.8)$ & $58(3.1)$ \\
\hline Depression & $214(2.9)$ & $1(0.2)$ & $81(3.3)$ & $71(2.8)$ & $61(3.3)$ \\
\hline Death & $385(5.2)$ & $0(0.0)$ & $6(0.2)$ & $107(4.2)$ & $272(14.7)$ \\
\hline Total & $2420(32.4)$ & $128(21.7)$ & $516(20.8)$ & $595(23.3)$ & $1181(63.9)$ \\
\hline
\end{tabular}

a Per 1000 persons.

${ }^{\mathrm{b}}$ Per 1000 persons within stratum. 